\title{
THE EFFECT OF MEDIUM INTENSITY PHYSICAL ACTIVITY ON BLOOD GLUCOSE LEVELS IN DIABETES MELLITUS
}

\author{
R.A. Tanzila ${ }^{1}, \mathrm{Ni}$ Made Elva Mayasari² Dita Azzahra Maso $^{3 *}$
}

\begin{abstract}
${ }^{1}$ Department of Physiology, Faculty of Medicine, Universitas Muhammadiyah Palembang, Indonesia 2Department of Cardiovascular, Faculty of Medicine, Universitas Muhammadiyah Palembang, Indonesia ${ }^{3}$ Undergraduate Programme, Faculty of Medicine, Universitas Muhammadiyah Palembang, Indonesia *Corresponding author email: ditaazzahra@ymail.com
\end{abstract}

\begin{abstract}
Diabetes mellitus (DM) is a chronic disease that increased every year and caused many complications. There are four pillars in the management of DM, namely education, nutrition, pharmacology and physical training. According to PERKENI, physical exercise for people with DM can be done 3-4x/week with a duration of 30 minutes. This study aims to determine the effect of exercise moderate activities carried out by Diabetes Mellitus in Muhammadiyah Hospital Palembang on blood sugar levels at a time. This study uses a quasi-experimental method with a total sample of 30 people who were obtained by total sampling. The research data was taken by checking blood sugar before and after physical activity with aerobic type, which is done $1 \mathrm{x} /$ week for four weeks by using Easy Touch GCU. Wilcoxon test results found a p-value of 0.285 which means moderate exercise activities carried out by people with diabetes in Palembang Muhammadiyah Hospital which is carried out once a week for four weeks does not affect blood sugar levels at the time.
\end{abstract}

Keywords: diabetes mellitus, chronic disease, blood glucose, exercise.

\section{Introduction}

Indonesia is the $4^{\text {th }}$ country with the highest number of diabetes mellitus in the world after India, China and the United States with an estimated number of people living with diabetes in 2000 as many as 8.4 million people and is expected to increase to 21,3 million sufferers in $2030 .{ }^{1}$ Meanwhile in South Sumatra, based on the data, found 49,318 people with diabetes. ${ }^{2}$

Apart from cardiovascular disease, DM is also one of the leading causes of kidney disease and blindness at the age of under 65 years, as well as amputation. Also, diabetes is a cause of amputation (which is not caused by trauma), disability, and death. Diabetes and its complications bring substantial economic losses to diabetics and their families, health systems and the national economy through direct medical costs, loss of jobs and income. $^{3}$

Physical exercise is one of the pillars of diabetes management. Regular physical exercise in type 2 DM provides cardiometabolic protection to prevent or reduce the rate of diabetes disease progression and complications through improving blood pressure and kidney function. The consensus on the management and prevention of type 2 diabetes mellitus from PERKENI in 2011 stipulates that a physical exercise program is carried out by doing daily physical activities and regular physical exercise 3-4 times a week for approximately 30 minutes. ${ }^{4}$ In Indonesia, the moderate exercise of exercise routine is only carried out once/week. The results of Werdhani's (2007) research show that no member does exercise $3 \mathrm{x}$ per week, according to the program. This study found that all members 
at the research site, namely KJS Pondalisa, had not exercised according to recommendations. ${ }^{5}$

Rehmaita's research (2017) shows that there is a significant effect on reducing blood sugar levels (KGD) in patients with type II diabetes mellitus due to diabetes exercise and walking. ${ }^{6}$ Other studies have shown that there is a relationship between physical activity and fasting blood sugar levels of people with Diabetes Mellitus type 2.7-8 Based on the description above, the research aimed to determine the effect of moderate-intensity physical activity on blood sugar at times carried out by Diabetes Mellitus sufferers at Muhammadiyah Palembang Hospital.

\section{Methods}

This research is a quasi-experimental group pre-post test. The sample of this study consisted of 30 respondents with type 2 diabetes mellitus who participated in the moderate-intensity exercise at Muhammadiyah Palembang Hospital. The sampling technique used total sampling. In this technique, all respondents who meet the inclusion requirements are people with type 2 diabetes mellitus, receive medication and take oral or injectable drugs regularly, can do physical activity and follow exercise movements, and are willing to sign an informed consent and participate in research once per week for four weeks to complete the study. Data was collected two times, namely once before doing moderate-intensity sports activities in the first week and once after doing moderateintensity sports activities in the fourth week by taking blood sugar while using Easy Touch GCU.

\section{Results}

Table 1. Univariate analysis

\begin{tabular}{cccc}
\hline $\begin{array}{c}\text { Blood glucose } \\
\text { level }\end{array}$ & $\begin{array}{c}\text { Mean } \mathbf{\pm} \text { Std. Deviation } \\
\text { (mmHg) }\end{array}$ & $\begin{array}{c}\text { Minimum } \\
\text { (mmHg) }\end{array}$ & $\begin{array}{c}\text { Maximum } \\
\text { (mmHg) }\end{array}$ \\
\hline Before & $158,13 \pm 52,236$ & 102 & 270 \\
\hline After & $153,53 \pm 56,963$ & 91 & 297 \\
\hline
\end{tabular}

In Table 1, it can be seen that of the 30 respondents before physical activity in the first week, the average was $158.13 \pm 52.236 \mathrm{mmHg}$ with a minimum value of $102 \mathrm{mmHg}$ and a maximum of $270 \mathrm{mmHg}$. Meanwhile, after physical activity at week four, the mean blood sugar was $153.53 \pm 56.963 \mathrm{mmHg}$ with a minimum value of $91 \mathrm{mmHg}$ and a maximum of $297 \mathrm{mmHg}$.

Table 2. Bivariate analysis

\begin{tabular}{cc}
\hline $\begin{array}{c}\text { Blood glucose } \\
\text { level }\end{array}$ & $\boldsymbol{p}$-value \\
\hline Before & 0,285 \\
\hline After & 0,285 \\
\hline
\end{tabular}

In Table 2 it can be seen that of the 30 respondents after the Wilcoxon test was carried out, the $p$-value $=0.285(p>0.05)$ which means that there is no effect of moderate- 
intensity physical activity carried out at Muhammadiyah Palembang Hospital on blood sugar levels when patients with diabetes mellitus type 2 .

\section{Discussion}

The results of the analysis of the effect of moderate-intensity physical activity carried out by type 2 diabetes mellitus sufferers at Muhammadiyah Palembang Hospital on blood sugar at times did not have a significant effect. The statistical test results obtained p-value $=0.285$, it can be concluded that moderate-intensity physical activity carried out by people with diabetes at Muhammadiyah Palembang Hospital with a frequency of 1 time per week for four weeks did not have a significant effect on blood sugar levels during diabetes patients.

Recommendations for physical exercise in patients with type 2 diabetes mellitus use the principle of FITT (Frequency, Intensity, Time, Type). According to this theory, there are several principles of physical training at Muhammadiyah Hospital that still do not meet the criteria. The principles of intensity and type at Muhammadiyah Hospital have met the criteria, namely moderate-intensity training with the type of aerobic exercise. Aerobic exercise should be in the moderate-intensity category, which is about 64-76\% of the maximum heart rate (HR max). Any form of aerobic exercise (including brisk walking) that uses large muscle groups and causes a continuous increase in heart rate is beneficial, and it is advisable to perform various types of physical activity. ${ }^{8}$ However, the frequency and time of physical exercise are not yet following existing theories, because the physical activity carried out at Muhammadiyah Hospital is only done once / week with a duration of 60 minutes. Per the theory of Tan (2015) aerobic exercise is carried out at least three days a week with a distance between exercises of no more than two consecutive days because of the temporary effect of exercise in improving insulin work.

Aerobic activity can be done in short sessions with a duration of at least 10 minutes per session, and these sessions can be done throughout the week. Moderate intensity of 150 minutes of aerobic exercise per week has been associated with reduced morbidity and mortality in observational studies in a wide variety of populations. The recommended frequency of regular physical exercise is three times a week, without any distance of two days not doing physical exercise at all. This is due to the effect obtained after one time doing physical exercise, namely increasing insulin sensitivity, but only within 24 to 72 hours. ${ }^{9}$ So it is essential for DM sufferers to do physical exercise every two days, to maintain insulin work so that glucose levels blood can remain stable. DM sufferers should also increase physical activity that moves a lot and reduce activities that do not move too much such as watching television

This is in line with the research conducted by Erlina (2010), there is a significant effect of diabetes exercise on blood sugar levels when type 2 diabetes patients are carried out three times per week for eight weeks with a p-value of 0.00611 and research conducted by Afrega ( 2019) The results of this study show that there is an effect of diabetes mellitus exercise on blood sugar levels in diabetes mellitus sufferers with a pvalue of 0.000 in the intervention group and 0.027 in the control group. ${ }^{10-12}$ Where the intervention has given is diabetes mellitus exercise with a frequency of 3 times per week for two weeks. 


\section{Conclusion}

There is no effect of moderate physical activity on blood sugar levels in people with diabetes mellitus.

\section{References}

1. WHO. 2016. Global Report On Diabetes. France: World Health Organization; 2016

2. Indonesian Ministry of Health Infodatin. 2014. Data and Information Center of the Ministry of Health, Republic of Indonesia: Situation and Analysis of Diabetes Mellitus. Jakarta: Ministry of Health Publication Media RI. quoted from www.depkes.go.id

3. Garnita, D. 2012. Risk Factors for Diabetes Mellitus in Indonesia (Sakerti Data Analysis 2007). FKM UI.

4. Adi, S, et al. 2015. Consensus on the Management and Prevention of Type 2 Diabetes Mellitus in Indonesia 2015. Executive Board of the Indonesian Endocrinology Association (PB Perkeni).

5. Werdhani, R. 2007. Regular Exercise Frequency and Blood Pressure Decrease in Pondalisa Heart Club, Jakarta, 2000 - 2005. National Public Health Journal. Faculty of Medicine Indonesia.

6. Rehmaita M, Tahlil T. 2017. The Effect of Diabetes Exercise and Walking on Decreasing Blood Sugar Levels in Type II Dm Patients at Krueng Barona Jaya Aceh Besar Community Health Center. Journal of Nursing (2017) 5: 2 ISSN: 23386371, e-ISSN 2550-018X.

7. Atsari, N, et al. 2016. Comparison of Medium Intensity Continuous Exercise and High Intensity Interval Exercise to Blood Glucose Control. MKB, Volume 48 No. 4, December 2016.

8. Tan B, et al. 2015. Exercise Prescription Guide. Exercise is Medicine Singapore. Changi General Hospital: Marshall Cavendish Editions.

9. Colberg, S.R., Sigal, R.J. \& Fernhall, B. 2010. Exercise and Type 2 Diabetes. Diabetes Care Journals, 33 (12), p.e147

10. PB Perkeni. 2006. Consensus on Management and Prevention of Diabetes Mellitus Type 2 in Indonesia. Jakarta.

11. Erlina, L. 2010. The Influence of Diabetes Exercise on Blood Glucose Levels of Type 2 DM Patients at the Regional Hospital of Sumedang District. Bandung Health Polytechnic Nursing Department.

12. Afrega, A. 2019. The Influence of Diabetes Mellitus Exercise on Blood Sugar Levels in Type 2 Diabetes Mellitus Patients at the UPT Puskesmas Gading Rejo in 2019. Muhammadiyah College of Health (Stikes) Muhammadiyah Nursing Undergraduate Study Program Pringsewu Lampung. 